\title{
МЕТОДОЛОГИЧЕСКИЕ ПОДХОДЫ К ИССЛЕДОВАНИЮ ИНФОРМАЦИОННО-ПСИХОЛОГИЧЕСКОЙ БЕЗОПАСНОСТИ
}

\author{
T.М. Краснянская \\ Московский гуманитарный университет \\ В.Г. Тылец \\ Московский государственный лингвистический университет
}

Аннотация: Статья посвящена введению в проблемную область изучения информационнопсихологической безопасности сиенарного и ресурсного подхода, и обоснования их практикоориентированного потенциала.

Ключевые слова: информационно-психологическая безопасность, информация, угрозы, ресурсный подход, сценарный подход, компетентностный подход, темпоральный подход

\section{METHODOLOGICAL APPROACHES TO THE STUDY OF INFORMATION AND PSYCHOLOGICAL SECURITY}

\author{
T.M. Krasnianskaya \\ Moscow University for the Humanities \\ V.G. Tylets \\ Moscow state linguistic university
}

\begin{abstract}
: the article is devoted to the introduction to the problem area of studying information and psychological security of scenario and resource approaches and substantiation of their practice-oriented potential.
\end{abstract}

Keywords: information and psychological security, information, threats, resource approach, scenario approach, competence approach, temporal approach

Преемственность понятий, активно использующихся в современном научном дискурсе и социальной практике, - «компьютеризация», «информатизация», «цифровизация», - высвечивает изменение социальной действительности, связанное с возрастанием значимости технической и технологической составляющей взаимодействия с информацией. Цивилизационное развитие достигло состояния, при котором информация уже априори воспринимается первостепенной ценностью, определяющей качество жизни человека (Краснянская, Тылец, 2015a). Наряду с этим, накопились факты использования информации против него: манипулирование, введение в заблуждение (обман), психологическое давление и пр. (Бубновская, Леонидова, 2019; Краснянская, Тылец, 2019а; Сударик, Здорова, 2018). В условиях увеличения в социуме роли информации и её продуктов при распространении их антигуманного использования приобретает актуальность поиск и изучение показателей успешности психологической адаптации человека к новой реальности. В качестве такого показателя может применяться 
категория информационно-психологической безопасности человека, оформляющаяся в течение последних десятилетий (Воронкина, 2019).

Обращение к соответствующей проблематике, прежде всего, в рамках классических для отечественной психологии личностного и субъектно-деятельностного подходов позволило на сегодняшний день достаточно детально изучить широкий спектр причинных оснований, сущностных особенностей угроз информационно-психологической безопасности человека, а также их последствий для его психики и социальной активности (Краснянская, Тылец, 2015b). Созданная теоретико-эмпирическая база позволяет перейти на новый этап поиска подходов к исследованию проблем информационно-психологической безопасности, связанных, в первую очередь, с пропедевтическим и кризисным разрешением ситуаций её нарушения.

Целью нашего исследования выступил анализ методологических подходов, обладающих потенциалом изучения практических проблем в сфере информационно-психологической безопасности.

Гипотезой выступило предположение, в соответствии с которым можно выделить несколько подходов к изучению информационно-психологической безопасности, задающих различные ракурсы решения её практико-ориентированных проблем.

Задачи исследования:

1) сформулировать практико-ориентированные подходы к изучению информационно-психологической безопасности;

2) содержательно раскрыть сущность информационно-психологической безопасности в рамках обозначенных подходов;

3) обозначить перспективы практико-ориентированного изучения информационно-психологической безопасности с использованием каждого рассматриваемого подхода.

Под информационно-психологической безопасностью нами, в целом, понимается психическое состояние человека, характеризующееся единством переживания защищённости от актуальных и прогнозируемых ему угроз в информационном пространстве со способностью оптимального использования возможностей этого пространства для своего развития в личностно значимом направлении. Информационно-психологическая безопасность характеризует состояние человека, сохраняющего в условиях информационных воздействий, в первую очередь неблагоприятных, контроль над своим актуальным состоянием и потенциалом развития с учётом сильных и слабых сторон собственного взаимодействия с информацией.

Несмотря на достаточно значительную историю изучения, до сих пор отсутствует единство научных позиций по вопросам соотнесения информационно-психологической безопасности и близкородственных ей категорий. Учитывая 
конструктивные особенности наименования, требуется, прежде всего, её сопоставление с категориями психологической и информационной безопасности.

Основываясь на современных наработках психологии безопасности, считаем неприемлемым ранее допускаемое отождествление информационно-психологической и психологической безопасности. Как психический феномен, по своим проявлениям (сущностной природе, структуре, субъектным и личностным эффектам) информационно-психологическая безопасность приближена к психологической безопасности, однако приобретает актуальность исключительно в связи с попаданием человека в неблагоприятные информационные условия и ситуации, содержащие проблемное для него информационное взаимодействие. Специфику информационно-психологической безопасности задаёт определяющая роль информации в изменении его индивидных, субъектных или личностных характеристик как предпосылки актуализации вопросов безопасности.

Это позволяет рассматривать информационно-психологическую безопасность как особую форму психологической безопасности, выделяемую по фактору воздействия, изменяющему состояние человека. По этому основанию в структуре психологической безопасности, наряду с информационно-психологической безопасностью (фактор воздействия - информация), можно выделить, например, коммуникативную (стратегия построения взаимодействия) и духовную (присваиваемые ценности) безопасность.

Информационная безопасность как технически и технологически обеспеченная практика поддержания защищённости информации и её инфраструктуры от несанкционированного доступа, использования, опубликования, искажения, уничтожения и прочих нежелательных действий при своём нарушении рассматривается нами объективным фактором постановки вопроса информационно-психологической безопасности (Краснянская, Тылец, 2019b). Информационно-психологическая безопасность человека в условиях нестабильной информационной безопасности может существенно изменяться. Вместе с тем, информационная безопасность, очевидно, выступает необходимым, но не достаточным фактором установления его информационно-психологической безопасности. В таком качестве целесообразным видится введение внутренних детерминант, возможно, психической (сенсорной, ментальной, эмоциональной) безопасности индивида, безопасности субъекта деятельности или психологической безопасности личности, способных опосредовать влияние на человека угроз информационной безопасности.

Принципиальным для рассмотрения проблемы мы считаем также признание вариативности и ресурсоёмкости природы информационно-психологической безопасности.

В качестве исследовательских подходов, обладающих потенциалом пропедевтического и кризисного практико-ориентированного решения проблем ин- 
Научные труды Московского гуманитарного университета

2020 № 5

формационно-психологической безопасности, нами позиционируются сценарный и ресурсный подходы.

Информационно-психологическая безопасность как специфическое психическое состояние человека обладает достаточной вариативностью своих характеристик. Изменяясь количественно по уровню интенсивности, она может также качественно трансформироваться по содержанию, в частности, по актуальным для неё угрозам, доминирующим эмоциям, ценностным приоритетам, мотивационным установкам.

Существенную роль в этой вариативности играет информационная среда, в которой человек находится: поток поступающей в некоторый момент информации определяет не только постановку самой проблемы информационно-психологической безопасности, но также характер воздействующих на него угроз и их объём. Наряду с объективными условиями информационного воздействия, особенности информационно-психологической безопасности задаются исходными индивидными, субъектными и личностными свойствами человека.

Сочетание объективных и субъективных условий определяет способность человека противодействовать угрозам информационно-психологической безопасности, определённым образом выстраивая субъектно-ситуационное взаимодействие, а, следовательно, состояние информационно-психологической безопасности в конкретный момент, тенденции её трансформации и траекторию вероятных изменений. Изучение всего массива таких условий и их последствий даёт возможности более или менее глубокого и точного предвидения вариантов (сценариев) развития информационно-психологической безопасности. Допущение широкого многообразия возможных сценариев информационно-психологической безопасности человека и практическая востребованность построения прогноза их структурно-содержательных особенностей в определённом пространственно-временном континууме требует использования исследовательских возможностей сценарного подхода.

В рамках сценарного подхода информационно-психологическую безопасность человека, с нашей точки зрения, целесообразно рассматривать в качестве среза его психических характеристик, целостно определяющих переживание им своей защищённости и воспроизводимости способности к развитию в личностно значимом направлении, в конкретной ситуации непрерывно изменяющегося информационного воздействия.

Особенностью сценарного подхода к изучению информационно-психологической безопасности человека нами видится обращение не к единичным характеристикам, а к комплексу её количественных и качественных характеристик, детерминируемых значительным массивом факторов. Изучение их взаимосвязи создаёт организационные и содержательные предпосылки для построения прогноза состояния информационно-психологической безопасности 
Научные труды Московского гуманитарного университета

2020 № 5

в заданной точке пространственно-временного континуума (в конкретной ситуации или условиях). Построение сценариев информационно-психологической безопасности применительно к социально или профессионально значимым условиям или ситуациям способно выступить основой для более эффективного построения и проведения по отношению к ним пропедевтических и кризисных мероприятий.

В обозначенном исследовательском контексте вспомогательная роль может быть делегирована темпоральному подходу, который позволяет сосредоточиться на выявлении особенностей информационно-психологической безопасности в некоторый момент её изменения (актуализации, падения, стабилизации, воссоздания, трансформации). В рамках темпорального подхода информационно-психологическая безопасность может рассматриваться в качестве состояния, характеризующего переживание человеком защищённости и способности к личностно значимому развитию, обладающего некоторой (ещё нераскрытой) динамикой. Использование данного исследовательского ракурса, ориентируя на учёт внутренних тенденций в изменении информационно-психологической безопасности во времени, повышает прогностическую точность описания её особенностей в некоторой отдалённой перспективе.

Информационно-психологическая безопасность человека в значительной степени зависит от его индивидных, субъектных и личностных характеристик, оказывающих на неё позитивное или негативное влияние. Исследования по проблеме позволяют предполагать множественность психических особенностей человека, релевантных для его информационно-психологической безопасности. Несомненной практической ценностью обладает выяснение модальности, объёма и возможности их практического использования для решения пропедевтических и кризисных задач в сфере информационно-психологической безопасности. Вместе с тем, эмпирический материал по этому аспекту проблематики и выводы по нему всё ещё остаются фрагментарными и несистематизированными. Подобного рода исследования наиболее перспективны, вероятно, с использованием ресурсного подхода.

В рамках ресурсного подхода информационно-психологическую безопасность человека представляется целесообразным анализировать как особое состояние переживания им защищённости и способности к личностно значимому развитию, определяемое комплексом некоторых ресурсов. Информационно-психологическая безопасность, соответственно, предстаёт перед исследователем в качестве состояния защищённости и развития человека, достигаемого им вследствие оптимального привлечения и использования своих ресурсов.

Особенностью ресурсного подхода является сосредоточение исследовательского интереса на характеристиках человека, обладающих потенциалом повышения уровня его информационно-психологической безопасности. Акцент при этом 
делается не на характере угроз информационно-психологической безопасности, а на возможности человека противостоять им на основе привлечения некоторых средств. По аналогии с психологической безопасностью, в данном случае, предполагаем допустимым обращение к возможностям не только внутренних (интеллектуальных, эмоциональных, волевых, мотивационно-ценностных), но и внешних (социальные нормы, обычаи, традиции, объекты и субъекты безопасности) ресурсов, находящихся не только в актуализированном, но и в виртуальном на текущий момент состоянии (Краснянская, Тылец, 2016).

Вспомогательным к ресурсному подходу в обозначенном контексте, вероятно, может восприниматься компетентностный подход, сосредоточенный на выявлении и изучении знаний, умений, навыков и способностей человека в определённой сфере.

Множественность ресурсов, которые человек может использовать для сохранения информационно-психологической безопасности, требует проведение исследований по изучению особенностей их иерархической структуры и механизмов управления ими, выявлению среди них ведущего ресурса и управляющего фактора и т.п. В целом, привлечение ресурсного подхода позволяет создать теоретико-эмпирическую базу для разработки программ, направленных на коррекцию и развитие параметров информационно-психологической безопасности человека.

Таким образом, в качестве основных практико-ориентированных подходов к изучению информационно-психологической безопасности человека нами рассматриваются сценарный и ресурсный подходы, вспомогательными к которым являются, соответственно, темпоральный и компетентностный подходы.

В статье реализовано введение в научную сферу сценарного и ресурсного подходов для изучения информационно-психологической безопасности человека и обоснование их в качестве основных методологических исследовательских подходов, обладающих потенциалом решения связанных с ней практико-ориентированных задач. Позволяя собрать эмпирический материал и на его основе выстроить прогностическую картину о наиболее вероятном состоянии информационно-психологической безопасности человека в конкретных условиях или ситуации, а также возможных ресурсах предотвращения и нейтрализации её угроз, данные подходы могут рассматриваться в качестве исследовательской базы превентивного и кризисного решения проблем в соответствующей области науки и практики.

\section{СПИСОК ЛИТЕРАТУРЫ}

Бубновская О.В., Леонидова В.В. (2019) Безопасность личности в образовательном пространстве в эпоху цифровизации // Сетевое образовательное взаимодействие в подготовке педагога информационного общества. Международная на- 
уч.-практич. конф. Владивосток: Дальневосточный федеральный ун-т. С. 358-364.

Воронкина Л.Б. (2019) Информационно-психологическая безопасность как основа профилактики агрессивности в молодежной среде // Университетские чтения 2019. Материалы научно-методических чтений. Пятигорск: ПГУ. С. 65-69.

Краснянская Т.М., Тылец В.Г. (2015a) Информационно-психологическая безопасность: угрозы личностному развитию и их преодоление // Развитие системы педагогического образования в современной России: антропологический аспект. Материалы XI Международ. науч.-практич. конф. / Под ред. Л.Л. Редько и др. Ставрополь. С. 54-59.

Краснянская Т.М., Тылец В.Г. (2015б) Классификация угроз информационно-психологической безопасности личности и основные подходы к их преодолению // Вестник Дагестанского государственного университета. № 4. С. 210-216.

Краснянская Т.М., Тылец В.Г. (2016) Психологическая характеристика виртуальных ресурсов безопасности личности // Веснік Магілёўскага дзяржаўнага ўніверсітэта імя А.А. Куляшова. Серыя С. Псіхолага-педагагічныя навукі: педагогіка, псіхалогія, методыка. № 1 (47). С. 37-43.

Краснянская Т.М., Тылец В.Г. (2019a) Субъектный импринтинг принципа безопасности в условиях массовых информационных воздействий // II Моисеевские чтения: культура как фактор национальной безопасности России. Доклады и материалы Общероссийской (национальной) научной конф. / Под ред. А.В. Костиной, В.А. Лукова. М.: МосГУ. С. 267-272.

Краснянская Т.М., Тылец В.Г. (2019б) Технологические составляющие обеспечения информационно-психологической безопасности личности в условиях дистанционного обучения // Информационные технологии и средства обучения. Т. 73 . № 5. C. 249-263. DOI: https://doi.org/10.33407/itlt.v73i5

Сударик А.Н., Здорова С.В. (2018) Психологические предпосылки социальной незащищенности граждан в коммуникативной сфере при применении высоких технологий // Актуальные проблемы обеспечения кибербезопасности. Материалы Всерос. Круглого стола. «Актуальные проблемы обеспечения кибербезопасности». М.: Моск. ун-т МВД РФ им. В.Я. Кикотя. С. 316-320.

Краснянская Татьяна Максимовна - доктор психологических наук, професcop, профессор кафедры социальной и этнической психологии, Московский гуманитарный университет; 111395, Россия, г. Москва, ул. Юности, 5; раб. E-mail: ktm8@ yandex.ru

Krasnyanskaya Tatyana Maksimovna, doctor of psychological sciences, professor, professor of the department of social and ethnic psychology of the Moscow University for the Humanities Postal address: Ostozhenka str., 38, bld.1. Moscow, Russian Federation, 119034; E-mail: tyletsvalery@yandex.ru

Тылец Валерий Геннадвевич - доктор психологических наук, профессор, профессор кафедры фонетики и грамматики французского языка, Московский государ- 
ственный лингвистический университет; 119034, Россия, г. Москва, ул. Остоженка, 38, стр.1; E-mail: tyletsvalery@yandex.ru

Tylets Valery Gennadievich, doctor of psychological sciences, professor, professor of the department of phonetics and grammar of the French language of the Moscow state linguistic university. Postal address: Ostozhenka str., 38, bld.1. Moscow, Russian Federation, 119034; E-mail: tyletsvalery@yandex.ru

\section{Для цитирования:}

Краснянская Т.М., Тылец В.Г. Методологические подходы к исследованию информационно-психологической безопасности // Научные труды Московского гуманитарного университета. 2020. №5. C. 54-61. DOI: https://www.doi.org/10.17805/trudy.2020.5.6 